\title{
Risk factors associated with disease progression in a cohort of patients infected with the 2019 novel coronavirus
}

\author{
Yulong Zhou ${ }^{1 \#}$, Zhicheng Zhang ${ }^{2 \#}$, Jie $\operatorname{Tian}^{1}$, Shaoyun Xiong ${ }^{1}$ \\ ${ }^{1}$ Department of Respiratory Medicine, ${ }^{2}$ Intensive Care Unit, The Ninth Hospital of Nanchang, Nanchang 330002, China \\ Contributions: (I) Conception and design: Y Zhou; (II) Administrative support: S Xiong; (III) Provision of study materials or patients: Z Zhang; (IV) \\ Collection and assembly of data: J Tian ; (V) Data analysis and interpretation: Y Zhou ; (VI) Manuscript writing: All authors; (VII) Final approval of \\ manuscript: All authors. \\ "These authors contributed equally to this work. \\ Correspondence to: Yulong Zhou; Shaoyun Xiong. Department of Respiratory Medicine, The Ninth Hospital of Nanchang, Nanchang 330002 , China. \\ Email: 282932253@qq.com; 2420580269@qq.com.
}

Background: The emerging infection of the 2019 novel coronavirus (2019-nCoV) in late December, 2019 in Wuhan, China, has caused an extreme health concern, with many patients having progressed to acute respiratory disease or other complications in a short period. Meanwhile, the risk factors associated with the disease progression still remain elusive.

Methods: A cohort of 17 patients with laboratory-confirmed 2019-nCoV infections who were admitted to the Ninth Hospital of Nanchang between January 28 and February 6, 2020, were enrolled in this study. All the patients received standardized treatment. The disease progression was evaluated every 7 days after admission. The clinical, radiologic, and laboratory characteristics were retrospectively analyzed, and the factors associated with the disease progression were screened by binary logistic regression analysis.

Results: The cohort comprised 11 women (64.7\%) and 6 men (35.3\%) between the ages of 18 to 70 years old. All patients had a reported history of contact with infection-confirmed patients. Fever (11/64.7\%) and cough $(8 / 47.1 \%)$ were the most common symptoms, whereas dyspnea $(2 / 11.8 \%)$ and fatigue $(3 / 17.6 \%)$ were rare, and there was no patient with diarrhea symptoms. There were 5 patients with aggravated disease at the first disease progression evaluation, and no patient received mechanical ventilation, transferred to the intensive care unit (ICU), or progressed to acute respiratory distress syndrome, septic shock, refractory metabolic acidosis, coagulation dysfunction, or death. Based on the disease progression, patients were divided into the non-aggravation group (12 cases) and the aggravation group (5 cases). There were no significant differences between the 2 groups with respect to their clinical characteristics. Chest computed tomography (CT) on admission revealed there were 8 patients (47.1\%) with invasive lesions found bilaterally on the lungs on multiple lobes, 4 patients $(23.5 \%)$ with invasive lesions on 1 lobe, and 5 patients $(29.4 \%)$ with normal chest CT. The aggravation group had1 patient (20.0\%) with invasive lesions on one lobe, $3(60.0 \%)$ with invasive lesions on multiple lobes, bilaterally, and 1 (20.0\%) with normal chest CT; meanwhile, the nonaggravation group had 3 patients $(25.0 \%)$ with invasive lesions on one lobe, 5 (41.7\%) with invasive lesions on multiple lobes, bilaterally, and $4(33.3 \%)$ with normal chest CT. No significant difference was found between the 2 groups. In the aggravation group, the total lymphocyte counts significantly decreased in comparison to that in the non-aggravation group. Further analysis showed that the $\mathrm{CD} 4^{+} \mathrm{T}$ cell count but not the $\mathrm{CD}^{+} \mathrm{T}$ cell count of the aggravation group was significantly lower than that of the non-aggravation group. Correlation analysis indicated total lymphocyte count was positively correlated with CD4 ${ }^{+} \mathrm{T}$ cell count, and no significant differences were found between the 2 groups in other laboratory measurements, including those of white blood cell (WBC) count, C-reactive protein (CRP), albumin, lactate dehydrogenase $(\mathrm{LDH})$, and D-dimer. Finally, a binary logistic regression model was used to identify the factors associated with the disease progression. It was found that total lymphocyte count was a risk factor associated with disease progression in patients infected with 2019-nCoV. 
Conclusions: A higher cell count of total lymphocytes may indicate a better outcome of the disease, and immune response may be a vital factor for directing disease progression in the early stage of 2019-nCoV infection.

Keywords: 2019 novel coronavirus (2019-nCoV); disease progression; aggravation; immune response; risk factors

Submitted Feb 18, 2020. Accepted for publication Mar 22, 2020.

doi: $10.21037 /$ apm.2020.03.26

View this article at: http://dx.doi.org/10.21037/apm.2020.03.26

\section{Introduction}

The emerging infection of a novel coronavirus was reported in late December, 2019, in Wuhan, China. The novel coronavirus was subsequently identified and provisionally named the 2019 novel coronavirus $(2019-\mathrm{nCoV})$, and human-to-human transmission was confirmed (1).

Coronaviruses (CoVs) are single-stranded RNA viruses, which circulate in nature, and can infect the respiratory, gastrointestinal, hepatic, and central nervous system tracts of various animal species, including humans, cattle, birds, and bats $(2,3)$. To date, $7 \mathrm{CoVs}$ that can infect humans have been described. Common human CoVs ( $\mathrm{HCoV}-\mathrm{OC} 43, \mathrm{HCoV}-$ $\mathrm{HKU} 1$, and $\mathrm{HCoV}-229 \mathrm{E}$ ) cause common colds but also severe lower respiratory tract infections in children and the elderly, while HCoVNL63 is considered to be an essential cause of pseudo-croup and bronchiolitis in children (4). The outbreaks of severe acute respiratory syndrome (SARS) in 2002-2003 (5,6) and Middle East respiratory syndrome (MERS)-CoV in $2012(7,8)$ had a serious impact on public health, with these 2 highly pathogenic CoVs causing severe respiratory disease.

The worsening of the clinical status and the complications leading to death in several cases (9-11) provoked a health concern for the current outbreak of 2019$\mathrm{nCoV}$ infection. Genome sequencing and analysis revealed that the genome of 2019-nCoV (GenBank accession MN908947) has the highest similarity (89\%) to 2003-SARS (GenBank accession MG772933) (12).

Thus far, the clinical symptoms have been described extensively in the published literature, and include fever, cough, and shortness of breath, with radiographs showing invasive lesions in the lungs. However, there is limited information in the existing literature regarding the influencing factors associated with disease progression in 2019-nCoV-infected patients. The current report analyzed the relationships of several clinical and laboratory factors with the disease progression in a cohort of 17 laboratoryconfirmed 2019-nCoV-infected patients. It is hoped that the information described in this report will offer a better understanding on the disease progression occurring after 2019-nCoV infection, and establish a basis to optimize the current therapeutic strategies.

\section{Methods}

\section{Patients}

A total of 33 patients withlaboratory-confirmed2019$\mathrm{nCoV}$ infections were admitted to the Ninth Hospital of Nanchang between January 28 and Februay 6, 2020. In total, 17 patients were included in the analysis, and the disease progress was evaluated every 7 days after the admission. This study was reviewed and approved by the Ethics Committee of the Ninth Hospital of Nanchang, and written informed consent was waived by the Ethics Committee in light of the urgent need to collect clinical data.

\section{Treatment}

All the patients were treated in strict accordance with the novel coronavirus infection diagnosis and treatment (the fifth trial version) formulated by the National Health Commission and Health Committee of China. To date, no antiviral treatment for coronavirus infection has been proven to be effective. Lopinavir/Ritonavir was empirically administered as an antiviral therapy, while corticosteroid therapy was given as a combined regimen when severe pneumonia was diagnosed. Oxygen support (e.g., nasal catheter, mask, high-flow oxygen therapy, non-invasive and invasive mechanical ventilation) was administered to patients according to the severity of hypoxaemia. 


\section{Data collection}

The epidemiological characteristics (including recent exposure history), clinical symptoms and signs, chest computed tomography (CT) characteristics, and laboratory findings were extracted from electronic medical records. Laboratory assessments consisted of white blood cell (WBC) count, C-reactive protein (CRP), D-dimer, albumin, lactate dehydrogenase $(\mathrm{LDH})$, total lymphocyte count, $\mathrm{CD} 4^{+}$cell count, and $\mathrm{CD}^{+}$cell count. The endpoint was a disease progression to aggravation after admission; because clinical observations were still ongoing, fixed time frame (i.e., within 28 days), admission to ICU, mechanical ventilation, and death, were not applied to these endpoints at the time of the study.

\section{Disease progression evaluation}

Disease progression was evaluated every 7 days after admission, and consisted of classification into 1 of 3 grades: (I) improvement: the body temperature is lower than before, respiratory symptoms are relieved, and lung CT shows that the lesion(S) appears to be more absorbed and dissipated than before; (II) no change: no significant change in body temperature, respiratory symptoms, or lung CT; (III) aggravation: the body temperature is higher than before, the respiratory symptoms are more serious, and the lesion(s) on lung CT is larger than before.

\section{Statistical analysis}

Continuous variables with Gaussian distribution were expressed as mean $\pm \mathrm{SD}$ and compared with the independent $t$ test, while continuous variables without Gaussian distribution were expressed as median (min, max) and compared with the Mann-Whitney U test. Categorical variables were expressed as number (\%) and compared by $\chi^{2}$ test or Fisher's exact test. Pearson's correlation was used to determine the correlation between total lymphocyte count and $\mathrm{CD}^{+} \mathrm{T}$ cell count. Binary logistic regression was used to screen the factors associated with the disease progression in 2019-nCoV-infected patients.

\section{Results}

\section{Demographic and clinical characteristics}

A total of 17 patients with confirmed infections were admitted to the Ninth Hospital of Nanchang. There were 11 women $(64.7 \%)$ and 6 men $(35.3 \%)$ in this cohort with ages ranging from 18 to 70 years old. All patients had a reported history of contact with infection-confirmed patients. The degree of clinical symptoms varied among this cohort of patients. Fever (11/64.7\%) and cough (8/47.1\%) were the most common symptoms, whereas dyspnea $(2 / 11.8 \%)$ and fatigue $(3 / 17.6 \%)$ were rare, and there were no patients with diarrhea symptoms. There were 5 patients (29.4\%) with coexisting disorders (e.g., hypertension, others). In this cohort, no patient received mechanical ventilation, transferred to the ICU, or progressed to acute respiratory distress syndrome (ARDS), septic shock, refractory metabolic acidosis, coagulation dysfunction, or death. For the first evaluation of disease progression (7 days after admission), there were 5 patients with aggravation. Based on the disease progression, patients were divided into the non-aggravation group (12 cases, 7 of which showed improvement and 5 of which showed no change) and the aggravation group (5 cases). As shown in Table 1, there were no significant differences between the 2 groups with respect to the clinical characteristics.

\section{Radiologic characteristics}

Chest CT on admission revealed that there were 8 patients $(47.1 \%)$ with invasive lesions found bilaterally on multiple lobes of the lungs, 4 patients $(23.5 \%)$ with invasive lesions on 1 lobe, and 5 patients (29.4\%) with normal chest CT. As shown in Figure 1, the aggravation grouphad1 patient (20.0\%) with invasive lesions on one lobe, $3(60.0 \%)$ with invasive lesions on multiple lobes, bilaterally, and 1 (20.0\%) with normal chest CT. Meanwhile, the non-aggravation group had 3 patients $(25.0 \%)$ with invasive lesions on one lobe, $5(41.7 \%)$ with invasive lesions on multiple lobes, bilaterally, and 4 (33.3\%) with normal chest CT. No significant difference was found between the 2 groups $(\mathrm{P}=0.777)$. Some representative radiologic features of Chest CT are shown in Figures 2-4.

On admission, chest CT showed a patchy shadow on the dorsal segment of the lower left lung with fuzzy edge. After 7-day treatment, the shadow on the dorsal segment of the lower left lung was reduced.

On admission, chest CT showed multiple patchy shadows on both lungs with fuzzy edges. After 7-day treatment, multiple patchy shadows on both lungs were enlarged.

On admission, chest CT showed patchy ground-glass 
Table 1 Clinical characteristics of the two groups

\begin{tabular}{|c|c|c|c|}
\hline $\begin{array}{l}\text { Clinical } \\
\text { characteristics }\end{array}$ & $\begin{array}{c}\text { Non-aggravation } \\
\text { group }(n=12)\end{array}$ & $\begin{array}{l}\text { Aggravation } \\
\text { group }(n=5)\end{array}$ & $P$ \\
\hline Age (year) & $41.50 \pm 14.31$ & $42.20 \pm 14.91$ & 0.929 \\
\hline Gender (n/\%) & & & 0.102 \\
\hline Female & $6 / 50.0 \%$ & $5 / 100.0 \%$ & \\
\hline Male & $6 / 50.0 \%$ & $0 / 0.0 \%$ & \\
\hline Fever (n/\%) & & & 1.000 \\
\hline Yes & $8 / 66.7 \%$ & $3 / 60.0 \%$ & \\
\hline No & $4 / 33.3 \%$ & $2 / 40.0 \%$ & \\
\hline Cough (n/\%) & & & 0.131 \\
\hline Yes & $4 / 33.3 \%$ & $4 / 80.0 \%$ & \\
\hline No & $8 / 66.7 \%$ & $1 / 20.0 \%$ & \\
\hline Dyspnea (n/\%) & & & 1.000 \\
\hline Yes & $2 / 16.7 \%$ & $0 / 0.0 \%$ & \\
\hline No & $10 / 83.3 \%$ & $5 / 100.0 \%$ & \\
\hline Fatigue (n/\%) & & & 0.191 \\
\hline Yes & $1 / 8.3 \%$ & $2 / 40.0 \%$ & \\
\hline No & $11 / 91.7 \%$ & $3 / 60.0 \%$ & \\
\hline \multicolumn{2}{|c|}{ Coexisting disorders (n/\%) } & & 0.600 \\
\hline Yes & $3 / 25.0 \%$ & $2 / 40.0 \%$ & \\
\hline No & $9 / 75.0 \%$ & $3 / 60.0 \%$ & \\
\hline
\end{tabular}

shadow on the middle lobe and lower lobe of the right lung. After 7-day treatment, the shadow on the middle lobe and lower lobe of the right lung showed no obvious changes.

\section{Laboratory findings}

The laboratory findings are summarized in Table 2. In the aggravation group, the total lymphocyte counts significantly decreased in comparison with that in the non-aggravation group, with the difference being statistically significant $(\mathrm{P}=0.021)$. The cell count of lymphocyte subtype $\mathrm{CD}^{+}$ $\mathrm{T}$ cell and $\mathrm{CD} 8^{+} \mathrm{T}$ cell were then further analyzed. It was found that the $\mathrm{CD}^{+} \mathrm{T}$ cell count in the aggravation group was significantly lower than that of the non-aggravation group with a statistical significance $(\mathrm{P}=0.034)$. Meanwhile, there was no significant difference between the 2 groups regarding theCD ${ }^{+} \mathrm{T}$ cell count. In addition, no significant differences were found between the 2 groups in other

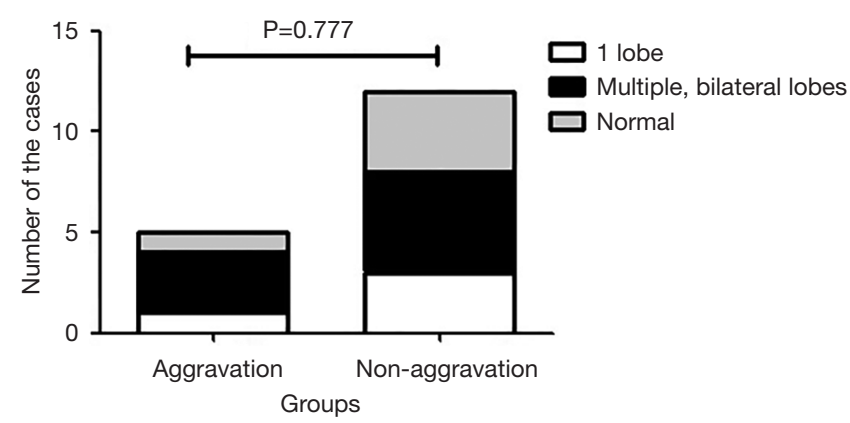

Figure 1 Radiologic characteristics of the two groups.

laboratory measurements, including those of WBC count, CRP, albumin, LDH, and D-dimer.

We further analyzed the correlation between total lymphocyte count and $\mathrm{CD}^{+} \mathrm{T}$ cell count. As shown in Figure 5, $\mathrm{CD}^{+} \mathrm{T}$ cell count was positively correlated with total lymphocyte count with a statistical significance $(r=0.940, P<0.0001)$.

\section{Logistic analysis of factors associated with disease progression}

A binary logistic regression model was used to identify the factors associated with the disease progression in patients infected with 2019-nCoV. As shown in Table 3, several independent variables were included in this model, and the univariate logistical analysis indicated that total lymphocyte count was a factor associated with disease progression in patients infected with 2019-nCoV.

\section{Discussion}

As of February 12, 2020, more than 40,000 cases have been confirmed as 2019-nCoV infection, with more than 1,000 fatal cases being reported throughout mainland China, and an increasing number of laboratory-confirmed cases being identified globally, including in the USA, Vietnam, Germany, etc. (13-16). The World Health Organization (WHO) has recently declared 2019-nCoV to be a public health emergency of international concern (16).

In an earlier published study (17) of a 41-patient cohort with laboratory-confirmed $2019-\mathrm{nCoV}$ infection, the mortality rate for $2019-\mathrm{nCoV}$ was as high as $15 \%$ (6 deaths among 41 patients). The high mortality maybe due to the fact that most of patients admitted had serious, sometimes fatal pneumonia, with some developing ARDS and 


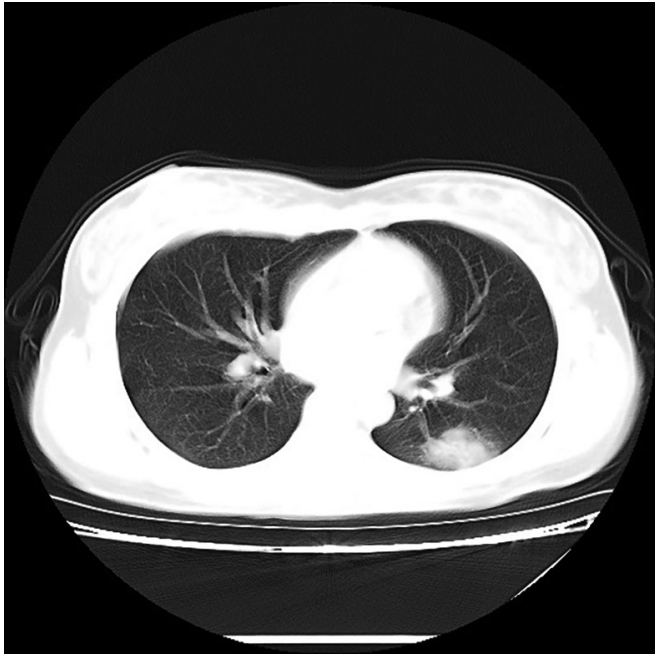

Before the treatment

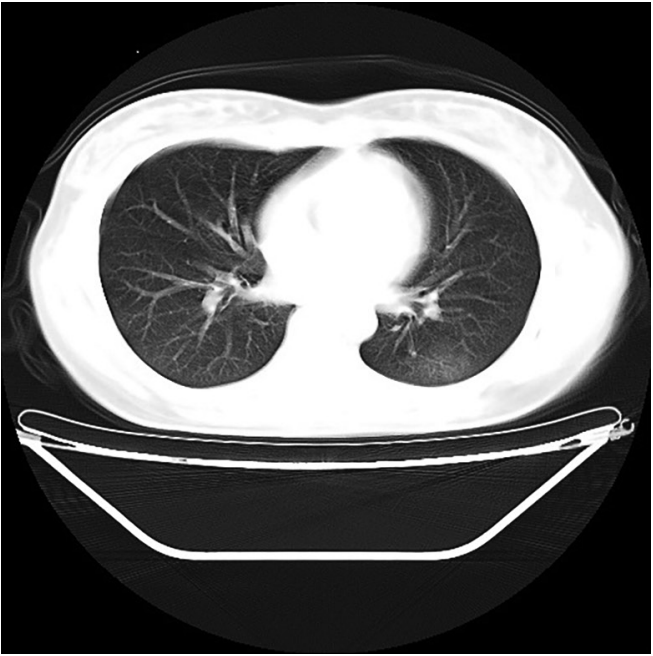

After the treatment

Figure 2 Representative radiologic features for improved patients.

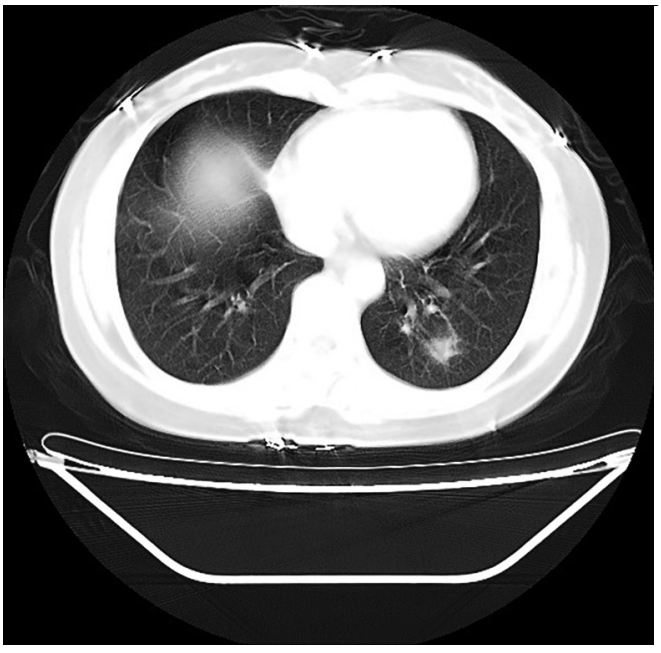

Before the treatment

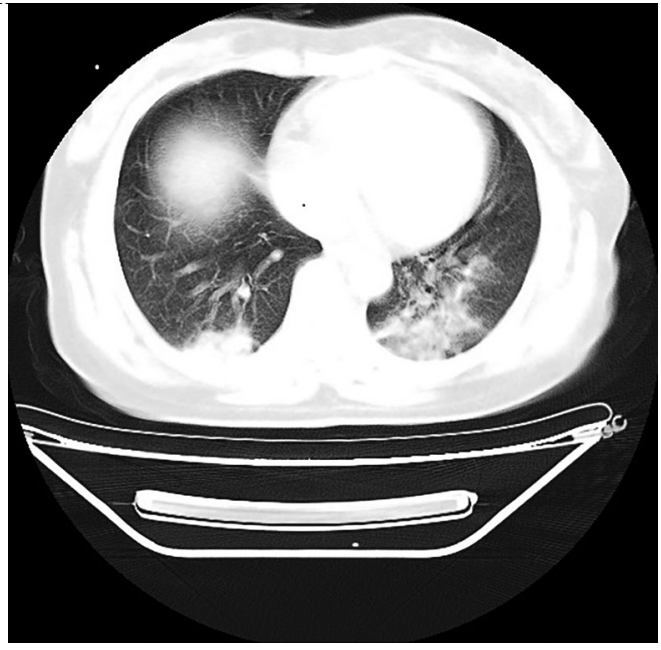

After the treatment

Figure 3 Representative radiologic features for aggravated patients.

requiring rapid ICU admission and oxygen therapy. The time between admission and ARDS was as short as 2 days in some cases. In the current study, we reported a cohort of 17 patients with laboratory-confirmed 2019-nCoV infection, who were admitted to the designated hospital (the Ninth Hospital of Nanchang) after January 28, 2020. By the first evaluation (7 days after admission) no patients had received mechanical ventilation, transferred to the ICU, or progressed to acute respiratory distress syndrome, septic shock, refractory metabolic acidosis, coagulation dysfunction, or death. This may be due to the fact that most patients in this cohort did not have severe illness, or the observation period of patients was too short (7 days) with the disease still ongoing. Despite a hospitalization period of only 7 days, the patients in this cohort experienced different illness outcomes, and 5 patients in this cohort progressed to aggravated illness.

In determining which patients progress to severe illness, 


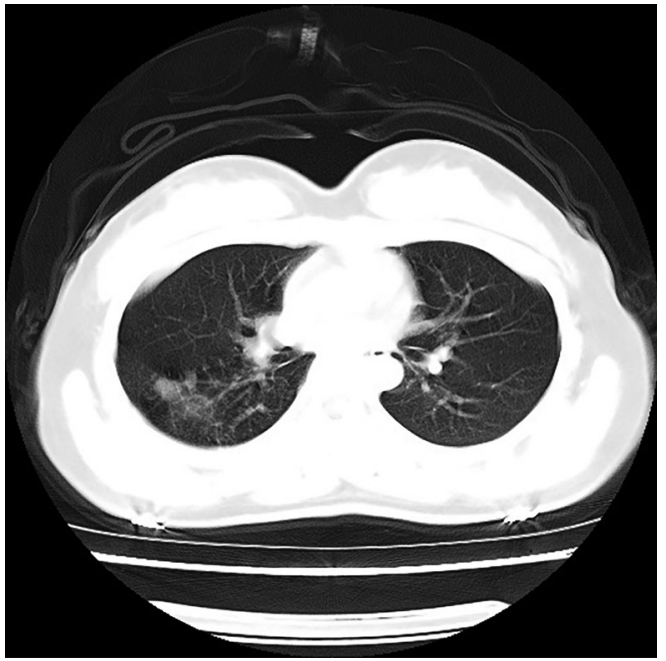

Before the treatment

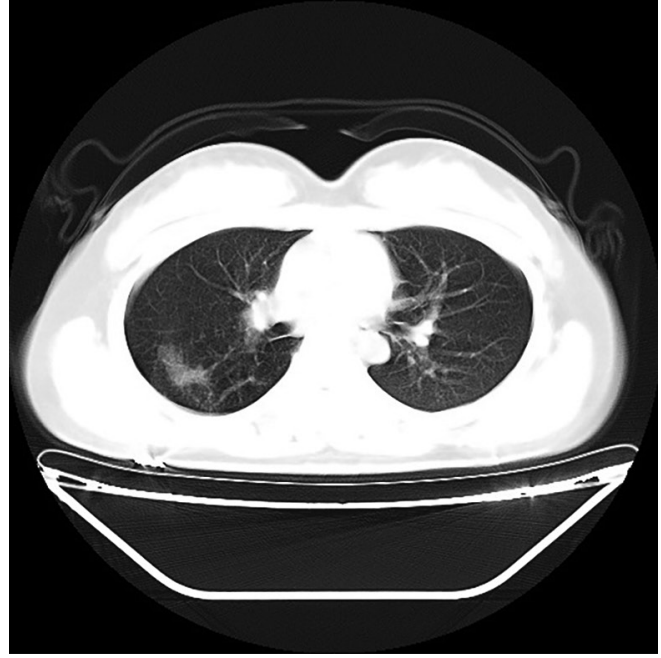

After the treatment

Figure 4 Representative radiologic features for patients without obvious change.

Table 2 Laboratory findings of the two groups

\begin{tabular}{lccc}
\hline $\begin{array}{l}\text { Laboratory } \\
\text { measurements }\end{array}$ & $\begin{array}{c}\text { Non-aggravation } \\
\text { group }(\mathrm{n}=12)\end{array}$ & $\begin{array}{c}\text { Aggravation } \\
\text { group }(\mathrm{n}=5)\end{array}$ & $\mathrm{P}$ \\
\hline WBC $\left(10^{9} / \mathrm{L}\right)$ & $5.65 \pm 2.08$ & $3.53 \pm 1.60$ & 0.059 \\
$\mathrm{CRP}(\mathrm{mg} / \mathrm{L})$ & $1.8(0.5,82.5)$ & $4.8(1.5,8.2)$ & 0.162 \\
Albumin $(\mathrm{g} / \mathrm{L})$ & $44.91 \pm 2.97$ & $46.00 \pm 3.24$ & 0.510 \\
LDH $(\mathrm{U} / \mathrm{L})$ & $180(137,320)$ & $157(148,246)$ & 0.792 \\
D-Dimer $(\mathrm{mg} / \mathrm{L})$ & $0.29 \pm 10.11$ & $0.28 \pm 0.11$ & 0.922 \\
Total $_{\text {lymphocyte }\left(10^{6} / \mathrm{L}\right)}$ & $1,223.0 \pm 442.7$ & $650.0 \pm 339.3$ & 0.021 \\
$\mathrm{CD}^{+} \mathrm{T}$ cell $\left(10^{6} / \mathrm{L}\right)$ & $698.2 \pm 267.4$ & $377.2 \pm 229.6$ & 0.034 \\
CD8 $^{+}$T cell $\left(10^{6} / \mathrm{L}\right)$ & $364(111,799)$ & $147(116,446)$ & 0.102 \\
\hline
\end{tabular}

WBC, white blood cell; CRP, C-reactive protein; $\mathrm{LDH}$, lactate dehydrogenase.

the progression at the early stage is likely very important to the outcome or the prognosis of the disease. We thus analyzed the differences between the aggravated patients and the non-aggravated patients in regards to the several clinical, radiologic, and laboratory findings, and attempted to identify the factors associated with disease progression. We found that clinical symptoms and signs had nothing to do with disease progression, and neither did the radiologic features of chest CT. Analysis of laboratory findings

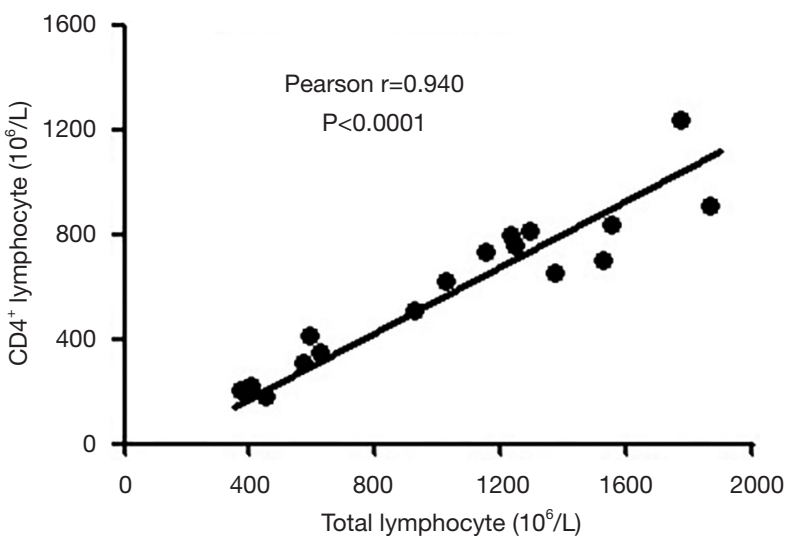

Figure 5 Correlation between total lymphocyte count and CD $4^{+}$ T cell count.

showed that the cell count of total lymphocyte and $\mathrm{CD}^{+}$ $\mathrm{T}$ cells in the aggravated patients was significantly reduced. Furthermore, a binary logistic regression model was used to screen the factors associated with disease progression; it was found that total lymphocyte count was the factor associated with the progression in 2019-CoV-infected patients. A higher cell count of total lymphocyte indicated a better outcome of the disease. However, $\mathrm{CD} 4^{+} \mathrm{T}$ cell count was not a factor associated with disease progression, and this may be due to the small number of patients in this study. Correlation analysis indicated that $\mathrm{CD}^{+} \mathrm{T}$ cell count was 
Table 3 Screening of factors associated with disease progression

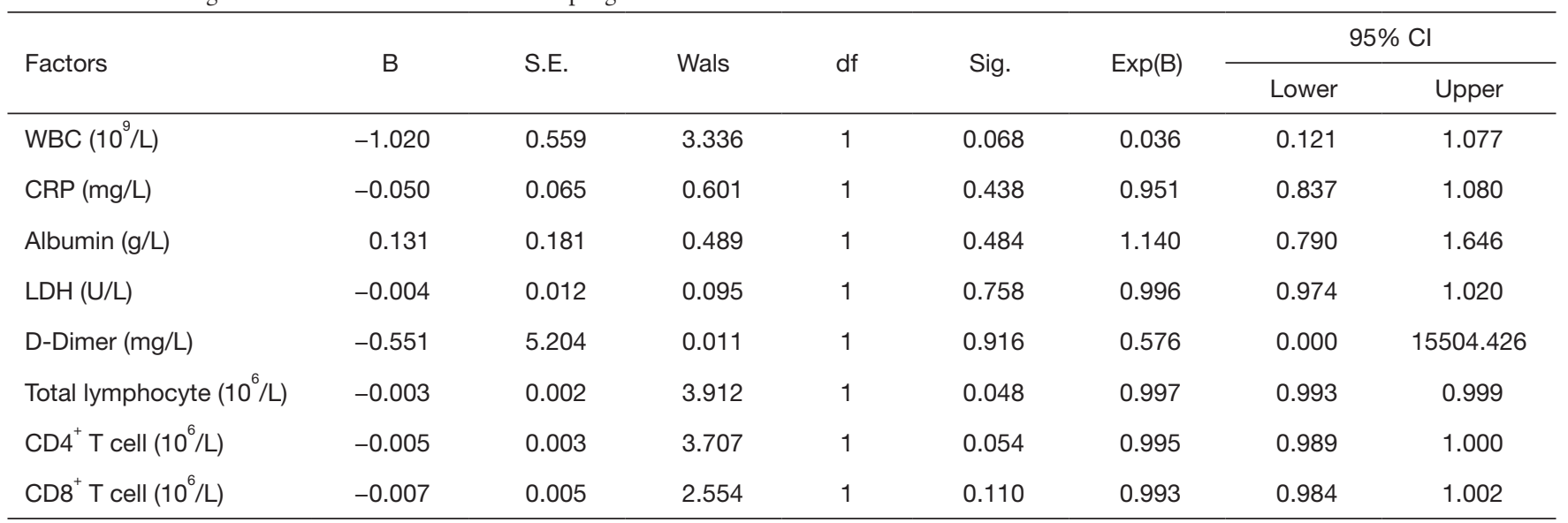

WBC, white blood cell; CRP, C-reactive protein; LDH, lactate dehydrogenase.

positively correlated with total lymphocyte count in this cohort of patients. This suggests that $\mathrm{CD}^{+} \mathrm{T}$ cells may be lymphocytes that regulate the immune response against 2019-nCoV in these patients; therefore, an in-depth study with a large sample size should be conducted to verify this.

It is well known that during virus infection, host factors trigger an immune response against the virus. Immune insufficiency or misdirection may increase viral replication and cause tissue damage. It has been reported that MERS$\mathrm{CoV}$ and SARS-CoV can cause fatal lower respiratory tract infections and extrapulmonary manifestations (18-20). Lymphocytes, especially $\mathrm{CD} 4^{+} \mathrm{T}$ cells and $\mathrm{CD} 8^{+} \mathrm{T}$ cells, have been shown to play a significant antiviral role by managing the fight against pathogens $(21) . \mathrm{CD}^{+} \mathrm{T}$ cells promote the production of virus-specific antibodies by activating T-dependent $\mathrm{B}$ cells. $\mathrm{CD} 8^{+} \mathrm{T}$ cells, meanwhile, are reported to play a vital role in eliminating $\mathrm{CoVs}$ in infected cells and inducing immune injury. In MERS-CoV, $\mathrm{CD}^{+} \mathrm{T}$ cells were found to be more susceptible to infection (22). In SARS-CoV, however, depletion of $\mathrm{CD} 8^{+} \mathrm{T}$ cells did not affect viral replication of SARS-CoV $(23,24)$, while depletion of $\mathrm{CD}^{+}{ }^{+} \mathrm{T}$ cells was associated with reduced pulmonary recruitment of lymphocytes and the neutralizing of antibody and cytokine production, resulting in a strong immune-mediated interstitial pneumonitis and delayed clearance of SARS-CoV from the lungs (25).

Based on the information from previous reports combined with the findings in this study, we believe that immune response is a vital factor directing disease progression. To our knowledge, this is the first study to report that total lymphocyte count and $\mathrm{CD}^{+} \mathrm{T}$ cell count are related with the outcome of the disease, with total lymphocyte count being a risk factor associated with the outcome of the disease. This suggests that immune response may be critical in directing disease progression at the early stage of $2019-\mathrm{nCoV}$ infection. We hope the findings of this study are helpful for optimizing the current therapeutic strategies in the treatment of $2019-\mathrm{nCoV}$ infection.

Some limitations in this study should also be addressed. Firstly, a number of cases might have caused statistical bias in the results. Moreover, the risk factors associated with disease progression were not assessed extensively. Secondly, few patients with severe illness were admitted, which made it difficult to assess the risk factors for mortality. Thirdly, the immune response in this cohort of patients was not studied in depth. However, the findings of this research may still provide some insight for future studies to identify which cell types, cytokines/chemokines, underlying mechanisms, etc. figure prominently in the disease severity, outcome, and prognosis of this infection. More effort should be made to answer these questions in future studies. To conclude, a higher cell count of total lymphocytes may indicate a better outcome of the disease, and immune response may be a vital factor directing disease progression at the early stage of 2019-nCoV infection.

\section{Acknowledgments}

Funding: None. 


\section{Footnotes}

Conflicts of Interest: The authors have no conflicts of interest to declare.

Ethical Statement: The authors are accountable for all aspects of the work in ensuring that questions related to the accuracy or integrity of any part of the work are appropriately investigated and resolved. This study was reviewed and approved by the Ethics Committee of the Ninth Hospital of Nanchang (No. 20200224), and written informed consent was waived by the Ethics Committee in light of the urgent need to collect clinical data.

Open Access Statement: This is an Open Access article distributed in accordance with the Creative Commons Attribution-NonCommercial-NoDerivs 4.0 International License (CC BY-NC-ND 4.0), which permits the noncommercial replication and distribution of the article with the strict proviso that no changes or edits are made and the original work is properly cited (including links to both the formal publication through the relevant DOI and the license). See: https://creativecommons.org/licenses/by-nc-nd/4.0/.

\section{References}

1. WHO. Novel coronavirus-China. Jan 12, 2020. Available online: http://www.who. int/csr/don/12-january-2020novel-coronavirus-china/en/ (accessed Jan 19, 2020).

2. Zhou P, Yang XL, Wang XG, et al. Discovery of a novel coronavirus associated with the recent pneumonia outbreak in humans and its potential bat origin. bioRxiv 2020. doi: 10.1101/2020.01.22.914952.

3. Chen Y, Liu Q, Guo D. Coronaviruses: genome structure, replication, and pathogenesis. J Med Virol 2020. doi: 10.1002/jmv.25681.

4. Yin Y, Wunderink RG. MERS, SARS and other coronaviruses as causes of pneumonia. Respirology 2018;23:130-7.

5. Al-Tawfiq JA, Zumla A, Memish ZA. Travel implications of emerging coronaviruses: SARS and MERS-CoV. Travel Med Infect Dis 2014;12:422-8.

6. Wilder-Smith A. The severe acute respiratory syndrome: impact on travel and tourism. Travel Med Infect Dis 2006;4:53-60.

7. Al-Tawfiq JA, Gautret P. Asymptomatic Middle East Respiratory Syndrome Coronavirus (MERS-CoV)
infection:Extent and implications for infection control: A systematic review. Travel Med Infect Dis 2019;27:27-32.

8. Baharoon S, Memish ZA. MERS-CoV as an emerging respiratory illness: A review of prevention methods. Travel Med Infect Dis 2019:101520.

9. Zhu N, Zhang D, Wang W, A Novel Coronavirus from Patients with Pneumonia in China, 2019. et al. A Novel Coronavirus from Patients with Pneumonia in China, 2019. N Engl J Med 2020;382:727-33.

10. Chan JF, Yuan S, Kok KH, et al. A familial cluster of pneumonia associated with the 2019 novel coronavirus indicating person-to-person transmission: a study of a family cluster. Lancet 2020;395:514-23.

11. Huang C, Wang Y, Li X, et al. Clinical features of patients infected with 2019 novelcoronavirus in Wuhan, China. Lancet 2020;395:497-506.

12. Cheng VCC, Wong SC, To KKW, et al. Preparedness and proactive infection control measures against the emerging Wuhan coronavirus pneumonia in China. J Hosp Infect 2020;104:254-5.

13. Phan LT, Nguyen TV, Luong QC, et al. Importation and human-to-human transmission of a novel coronavirus in Vietnam. N Engl J Med 2020;382:872-4.

14. Rothe C, Schunk M, Sothmann P, et al. Transmission of 2019-nCoV infection from an asymptomatic contact in Germany. N Engl J Med 2020;382:970-1.

15. Holshue ML, DeBolt C, Lindquist S, et al. First case of 2019 novel coronavirus in the United States. N Engl J Med 2020;382:929-36.

16. WHO main website. Available online: https://www.who. int (accessed February 5th, 2020)

17. Huang CL Wang YM, Li XW, et al. Clinical features of patients infected with 2019 novel coronavirus in Wuhan, China. Lancet 2020;395:497-506.

18. Chan JF, Lau SK, To KK, et al. Middle East respiratory syndrome coronavirus: another zoonotic betacoronavirus causing SARS-like disease. Clin Microbiol Rev 2015;28:465-522.

19. Cheng VC, Lau SK, Woo PC, et al. Severe acute respiratory syndrome coronavirus as an agent of emerging and reemerging infection. Clin Microbiol Rev 2007;20:660-94.

20. Sato K, Misawa N, Takeuchi JS, et al. Experimental Adaptive Evolution of Simian Immunodeficiency Virus SIVcpz to Pandemic Human Immunodeficiency Virus Type 1 by Using a Humanized Mouse Model. J Virol 2018. doi: 10.1128/JVI.01905-17. 
21. Cecere TE, Todd SM, Leroith T. Regulatory T cells in arterivirus and coronavirus infections: do they protect against disease or enhance it? Viruses 2012;4:833-46.

22. Maloir Q, Ghysen K, von Frenckell C, et al. Acute respiratory distress revealing antisynthetase syndrome. Rev Med Liege 2018;73:370-5.

23. Channappanavar R, Fett C, Zhao J, et al. Virus-specific memory CD8 $\mathrm{T}$ cells provide substantial protection from lethal severe acute respiratory syndrome coronavirus

Cite this article as: Zhou Y, Zhang Z, Tian J, Xiong S. Risk factors associated with disease progression in a cohort of patients infected with the 2019 novel coronavirus. Ann Palliat Med 2020;9(2):428-436. doi: 10.21037/apm.2020.03.26 infection. J Virol 2014;88:11034-44.

24. Ng OW, Chia A, Tan AT, et al. Memory T cell responses targeting the SARS coronavirus persist up to 11 years postinfection. Vaccine 2016;34:2008-14.

25. Chen J, Lau YF, Lamirande EW, et al. Cellular immune responses to severe acute respiratory syndrome coronavirus (SARS-CoV) infection in senescent BALB/c mice: CD4+ $\mathrm{T}$ cells are important in control of SARS-CoV infection. J Virol 2010;84:1289-301. 